\title{
Malignancy is More Common in Uremic Patients: Our Four Cases Diagnosed with Solid Organ Malignancy in Six Month Period and a Mini Review
}

\author{
${ }^{*}$ Corresponding Author \\ Ali Gürel

\section{Article History} \\ Received: 01.11 .2019 \\ Accepted: 08.11 .2019 \\ Published: 14.11 .2019
}

Ali Gürel", Mustafa Akel, Turgay Selçuk, Garip Bekfilavioğlu, Aysun Gürbüzcan

Adıyaman University Medical Faculty, Internal Medicine Department, Adıyaman, Turkey

\begin{abstract}
Introduction: Chronic kidney disease (CKD) is rapidly increasing and is a risk factor for many diseases such as malignancies. Case presentations: We represent our four hemodialysis patients diagnosed with solid organ malignancy in six month period. Discussion: Increased prevalence of malignancy in CKD has been known for a long time and clinicians should be careful about the symptoms and findings suggestive of malignancy.
\end{abstract}

Keywords: Chronic kidney disease, uremia, dialysis, transplantation, cancer, malignancy.

\section{INTRODUCTION}

Chronic kidney disease (CKD) is a rapidly increasing chronic disease and there is over than 1 million people under dialysis treatment all over the world. All other organs may be affected by CKD thus cardiovascular diseases and cancers are more common in this population. Uremia is associated especially with urinary, gastrointestinal, respiratory, haematological system, thyroid, lip and soft tissue malignancies and also poor cancer outcomes [1, 2]. Additionaly, it's known that renal transplantation and hemodialysis are also having association with malignancies [3, 4].

We report our four patients on hemodialysis treatment for a long time and diagnosed as cancer, in order to call attention to the relationship between uremia and malignancies.

\section{Case Presentations}

Case 1: A 41-year-old male patient undergoes hemodialysis 3 days a week for 20 years due to CKD etiology of glomerulonephritis. The patient was evaluated with complaints of abdominal pain, loss of appetite and weight loss. Physical examination revealed tenderness in the right upper quadrant of the abdomen and there was no defense or rebound. The patient underwent contrast-enhanced abdominal CT scan and mass lesions AND wall thickness consistent with ascending colon tumor and liver metastasis were detected. Because the patient had lesions filling the liver segment 4-5-6-7-8, an incisional biopsy was taken. Incisional biopsy was evaluated as poorly differentiated adenocarcinoma. Chemotherapy was planned according to the tumor histology. The patient was operated and, because of the lesions filling 4-5-6-7-8 segments during the operation, the patient was accepted as inoperable and, incisional biopsy was taken. Incisional biopsy revealed poorly differentiated adenocarcinoma and less likely hepatocellular carcinoma.

Copyright @ 2019: This is an open-access article distributed under the terms of the Creative Commons Attribution license which permits unrestricted use, distribution, and reproduction in any medium for non commercial use (NonCommercial, or CC-BY-NC) provided the original author and source are credited. 


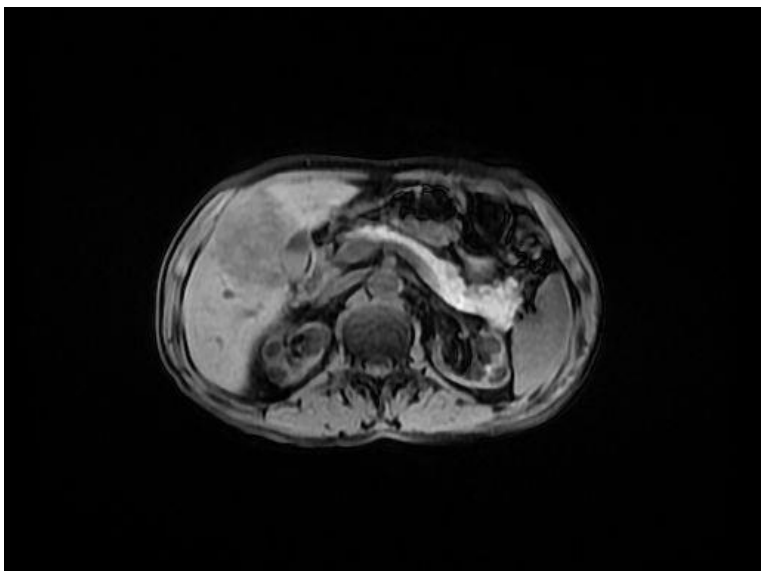

Fig-1: A heterogeneous mass lesion compatible with liver metastasis in case 1

Case 2: A 54-year-old male patient with CKD due to the etiology of hypertension undergoes hemodialysis 3 days a week for 5 years. The patient was evaluated with complaints of loss of appetite, fullness in the left upper quadrant and stomach pain. The physical examination of the patient revealed tenderness in the epigastric region and the traube area was closed. Spleen size was measured $165 \mathrm{~mm}$ in abdominal ultrasonography. CT revealed a mass lesion in the tail portion of the pancreas, and an irregular thickening of the duodenal wall. The postoperative biopsy of the patient was in favor of pancreatic malignancy and is under follow-up and treatment with post-operative chemotherapy.

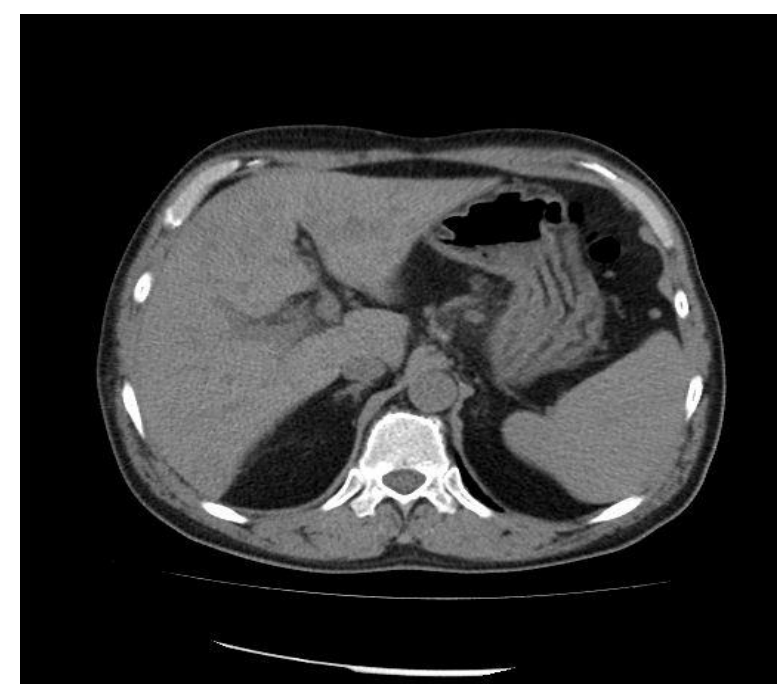

Fig-2: Diffuse wall irregularity / thickening of the duodenum in case 2

Case 3 \& 4: Two male patients in 55 and 72 years old under hemodialysis were evaluated because of painless macroscopic hematuria. Ultrasonography revealed wall thickening of bladder. Cystoscopy revealed irregular wall thickening and histopathologic result of the cystoscopic biopsy materials were compatible with transitional cell carcinoma of bladder for both of patients. For both patients radical cystectomy and ureterostomy was performed and then, they are under follow-up and treatment with chemotherapy.

\section{Discussion}

Uremia is associated with an increased risk of urinary tract, digestive tract and thyroid cancers, but also with a reduced risk of prostate cancer in men [1].

Analgesic nephropathy as a result of analgesics abuse and aristolochic acid nephropathy (Chinese herb nephropathy) and the Balkan-endemic nephropathy are associated with urothelial cancers [5-7].

In transplantation patients lymphoma and skin cancer incidence increase [8]. In dialysis patients immune dysfunction and, immunosuppressive or cytotoxic therapy for various glomerulonephritis or vasculitides cause cancers with viral etiology. Acquired cystic kidney disease is also a risk factor for renal cell carcinoma because of DNA damage [9].

In contrast with cancer risk associated with dialysis and transplantation, the potential of early stage CKD as a risk factor for cancer is not established. 
All four of our patients were under hemodialysis treatment for long years. In six month period, of these patients; one was diagnosed as gastrointestinal system cancer, one was diagnosed as pancreas cancer and two were diagnosed as bladder cancer.

The increased prevalence of malignancy in CKD has been known for a long time and clinicians should be careful about the symptoms and findings suggestive of malignancy in this patient group and make a detailed evaluation in order not to skip the cases.

\section{REFERENCES}

1. Wong, G., Staplin, N., Emberson, J., Baigent, C., Turner, R., Chalmers, J., ... \& Wang, J. J. (2016). Chronic kidney disease and the risk of cancer: an individual patient data meta-analysis of 32,057 participants from six prospective studies. BMC cancer, 16(1), 488.

2. White, S.L., Chadban, S.J., Jan, S., Chapman, J.R., Cass, A. (2008). How can we achieve global equity in provision of renal replacement therapy? Bull World Health Organ. 86(3):229-37.

3. Herr, H.W., Engen, D.E., Hostetler, J. Malıgnancy in uremıa: dialysıs versus transplantation. The Journal of Urology; $0022-5347$ 179/1215-0584\$02.00/0.

4. Stengel, B.(2010). Chronic kidney disease and cancer: a troubling connection. J Nephrol, 23(3): 253-262.

5. Mahony, J.F., Storey, B.G., Ibanez, R.C., Stewart, J.H. (1977). Analgesic abuse, renal parenchymal disease and carcinoma of the kidney or ureter. Aust N Z J Med, 7:463-469.

6. Debelle, F.D., Vanherweghem, J.L., Nortier, J.L.(2008). Aristolochic acid nephropathy: a worldwide problem. Kidney Int, 74:158169.

7. Vanherweghem, J.L., Depierreux, M., Tielemans, C. (1993). Rapidly progressive interstitial renal fibrosis in young women: association with slimming regimen including Chinese herbs. Lancet, 341:387-391.

8. Buell, J.F., Gross, T.G., Woodle, E.S. Malignancy after transplantation. Transplantation, 80(Suppl):S254-264.

9. Mandayam, S., Shahinian, V.B. (2008). Are chronic dialysis patients at increased risk for cancer? J Nephrol, 21:166-174. 